\title{
The calcitonin gene-related peptide receptor antagonist MK-8825 decreases spinal trigeminal activity during nitroglycerin infusion
}

Stephan Feistel, Stephanie Albrecht and Karl Messlinger

\begin{abstract}
Background: Calcitonin gene-related peptide (CGRP) and nitric oxide (NO) are regarded as key mediators in migraine and other primary headaches. Migraineurs respond to infusion of nitroglycerin with delayed headaches, and inhibition of CGRP receptors has been shown to be effective in migraine therapy. In animal experiments nitrovasodilators like nitroglycerin induced increases in spinal trigeminal activity, which were reversed after inhibition of CGRP receptors. In the present study we asked if CGRP receptor inhibition can also prevent spinal trigeminal activity induced by nitroglycerin.
\end{abstract}

Methods: In isoflurane anaesthetised rats extracellular recordings were made from neurons in the spinal trigeminal nucleus with meningeal afferent input. The non-peptide CGRP receptor inhibitor MK-8825 (5 mg/kg) dissolved in acidic saline ( $\mathrm{pH} 3.3$ ) was slowly infused into rats one hour prior to prolonged glyceryl trinitrate (nitroglycerin) infusion $(250 \mu \mathrm{g} / \mathrm{kg} / \mathrm{h}$ for two hours).

Results: After infusion of MK-8825 the activity of spinal trigeminal neurons with meningeal afferent input did not increase under continuous nitroglycerin infusion but decreased two hours later below baseline. In contrast, vehicle infusion followed by nitroglycerin was accompanied by a transient increase in activity.

Conclusions: CGRP receptors may be important in an early phase of nitroglycerin-induced central trigeminal activity. This finding may be relevant for nitroglycerin-induced headaches.

Keywords: CGRP receptor antagonist, Nitroglycerin, Trigeminal nucleus caudalis, Extracellular recording, Headache, Migraine

\section{Background}

Calcitonin gene-related peptide (CGRP) and nitric oxide (NO) are regarded as key mediators in the generation of migraine and other primary headaches $[1,2]$, based on several clinical data. CGRP has been found at elevated concentrations in jugular venous blood and saliva during attacks of migraine and cluster headache attacks [3-5], though this finding is not without contradiction [6]. Infusion of low doses of CGRP caused delayed migrainelike headaches in a group of migraineurs different to healthy control persons [7], possibly indicating a special sensitivity for this neuropeptide associated with migraine predisposition. Furthermore, migraine and cluster headache

\footnotetext{
* Correspondence: messlinger@physiologie1.uni-erlangen.de Institute of Physiology and Pathophysiology, University of Erlangen-Nürnberg, Universitätsstr 17, 91054 Erlangen, Germany
}

attacks can be treated with triptans, which is paralleled by normalisation of CGRP levels [3,8], or by CGRP receptor inhibitors like olcegepant (BIBN 4096BS) and telcagepant (MK-0974) [9-11]. Likewise, nitrovasodilators such as nitroglycerin can induce delayed migraine-like headaches in migraineurs [12] and other types of headaches in primary headache patients $[13,14]$. Blockade of the endogenous NO generation with an unspecific NO synthase inhibitor was successful in alleviating migraine pain [15], while selective inhibitors of the inducible NO synthase seemed to be ineffective in reducing or preventing migraine pain [16,17]. From these clinical data it can be concluded that endogenous CGRP and NO, most likely produced from neuronal or endothelial NO synthases, may play a role in the generation of migraine pain and other primary headaches. 
The clinical data are paralleled by animal experiments demonstrating the involvement of CGRP and $\mathrm{NO}$ in meningeal nociception, which is assumed to underlie the generation of headaches. Particularly, electrophysiological recordings in the rat spinal trigeminal nucleus caudalis from neurons that receive afferent input from meningeal tissues provide a reliable integrative measure of trigeminal activity. Infusion of the nitrovasodilators sodium nitroprusside (SNP) and nitroglycerin (glyceryl trinitrate, GTN) induced ongoing activity of spinal trigeminal neurons with meningeal afferent input [18], resembling the clinical experiments in migraineurs. The increase in activity started after 20-40 min and plateaued after 1-2 hours. Conversely, L-NAME, a nonspecific inhibitor of endogenous NO production, reduced the pre-existing spontaneous activity to about the half [19]. Similarly, the CGRP receptor antagonist olcegepant (BIBN4096BS) applied intravenously decreased both spontaneous and heat-evoked spinal trigeminal activity in a dose-dependent manner [20]. Importantly, the activity evoked by SNP and nitroglycerin was also decreased after CGRP receptor blockade to the preexisting level, suggesting an interaction of CGRP and NO mechanisms in neuronal activity evoked by nitrovasodilators [18].

In the present study we have used MK-8825, a new potent inhibitor for rat CGRP receptors, which showed concentration-dependent inhibition of capsaicin-evoked dermal blood flow with an $\mathrm{EC}_{50}$ of about 7.4 $\mu \mathrm{M}$ [21]. MK-8825 is structurally related to the CGRP receptor inhibitor MK-3207, which proved to be effective in the acute treatment of migraine $[9,11]$.

The rationale for the present study was to examine if CGRP receptor blockade by MK-8825 can prevent the increase in neuronal activity induced by nitroglycerin using the aforementioned model of spinal trigeminal recordings. Answering this question may reveal if CGRP receptors are involved in the nitroglycerin-induced promotion of neuronal activity and may have clinical relevance regarding the time of intervention with a CGRP receptor antagonist during the development of migraine attacks.

\section{Methods}

\section{General procedures}

The study was performed in accordance with the ethical guidelines of the International Association for the Study of Pain and the German laws for animal protection and treatment of laboratory animals. The protocol was reviewed by an ethics committee and authorised by the local district government.

Twenty-eight adult male Wistar rats, bred and held in the Institute's own animal house, with body weights ranging from 250 to $410 \mathrm{~g}$ were used. Rats were initially anaesthetised by breathing 4\% isoflurane (Forene, Abbott, Wiesbaden, Germany) using an evaporator system (Vapor 19.3, Dräger, Lübeck, Germany). After quick insertion of a tracheal tube they were artificially ventilated (Rodent Ventilator, Ugo Basile, Comerio VA, Italy) with $2 \%$ isoflurane in oxygen-enriched room air. Catheters were introduced into the right femoral artery and vein to record systemic blood pressure and to administrate substances. The arterial catheter was permanently perfused with saline (rate $0.2 \mathrm{ml} / \mathrm{h}$ ) supplemented with $1 \mathrm{IU} / \mathrm{ml}$ heparin (Heparin-Natrium-5000-ratiopharm, Ulm, Germany). Endexpiratory $\mathrm{CO}_{2}$ was monitored (Artema MM 200, Karl Heyer, Bad Ems, Germany) and held at 3\% by modulating the ventilation frequency between 70 and 100 strokes per minute, which suppressed spontaneous breathing. Body temperature was measured by a rectal probe and maintained at $37-37.5^{\circ} \mathrm{C}$ by a feedback controlled heating pad (TKM 0902, Föhr Medical Instruments, Frankfurt, Germany). Arterial pressure was between 70 and $100 \mathrm{mmHg}$ (Pressure Monitor BP-1, World Precision Instruments, Sarasota, Florida). The vital parameters were recorded during the whole experiment. The depth of narcosis during the experiment was constant, so that noxious pinch stimuli did not evoke nociceptive reflexes or changes in arterial blood pressure. At the end of the experiment the animals were euthanised by intravenous injection of an overdose of thiopental (Trapanal, Nycomed, Konstanz, Germany).

\section{Specific surgery}

The animals were transferred to a stereotaxic frame to hold the head in a fixed horizontal position using ear bars and a snout clamp. The skin was cut along the midline from the bregma to the lamda and the skin flaps were retracted laterally. The right parietal bone was carefully trepanised under liquid cooling using a dental drill to expose the dura mater in the cranial window. Care was taken to keep the dura mater intact and to avoid bleeding from dural blood vessels. The dura was protected from drying with $0.9 \%$ saline during the experiment. The neck muscles were detached from their insertions, separated in the midline and held apart with a clamp. The medullary brainstem was made accessible by cutting the atlanto-occipital ligament and the spinal dura underneath.

\section{Recordings}

For extracellular recordings of signals a custom-made carbon fibre glass electrode was inserted into the spinal trigeminal nucleus caudalis of the ipsilateral medulla. Using a microstepper, the electrode was moved through the brainstem at steps of $2.5 \mu \mathrm{m}$. Single units with meningeal receptive fields were detected by their firing of action-potentials in response to mechanical probing of 
the parietal dura mater. Signals were filtered, amplified and processed (CED 1401, Cambridge Electronic Design, Cambridge, UK). Spike-analysis was done offline using the discharges generated by mechanical stimulation of meningeal receptive fields as a template (Spike 2 software application, Cambridge Electronic Design).

At the end of the experiments the recording position relative to the obex was assessed by a two-dimensional micrometer system. In some experiments an electric lesion was made by anodal current passed through the recording electrode, and after thiopental injection the animal was perfused in deep anaesthesia through the left ventricle with saline followed by paraformaldehyde solution (4\%) for fixation. The brainstem was dissected and histologically processed to localise the recording site.

\section{Experimental protocols}

When the neuronal activity of a unit was visibly stable, its baseline was recorded for a period of $30 \mathrm{~min}$ without any treatment. In 12 experiments the CGRP receptor antagonist MK-8825 (5 mg/kg) dissolved in saline $(1 \mathrm{ml} / \mathrm{kg}$ body weight, $\mathrm{pH}$ 3.3) was i.v. infused at a constant rate within a period of 10 minutes and the recording was continued for further 50 minutes (see Figure 1). In 11 control experiments vehicle (buffered saline, $\mathrm{pH}$ 3.3) was infused instead of MK-8825, which was a possible confounding factor. Stimulation with acidic solutions can cause sensitisation of spinal trigeminal neurons with receptive fields in the rodent cranial dura mater [22]. The infusion of MK-8825 or vehicle was followed by a continuous infusion of nitroglycerin (GTN, $250 \mu \mathrm{g} / \mathrm{kg} / \mathrm{h}$ ) over a period of $120 \mathrm{~min}$. The infusion rate of nitroglycerin was low enough to avoid lowering of systemic blood pressure by more than $5 \mathrm{mmHg}$, as figured out in previous experiments [18]. In six additional experiments nitroglycerin was infused at the same rate without preadministration of MK-8825 or vehicle.

\section{Chemicals}

CGRP receptor antagonist MK-8825 (courtesy of the Merck \& Co. Inc., NJ, USA) was dissolved in acidic saline $(\mathrm{pH}$ 3.3) and i.v. injected at a concentration of $5 \mathrm{mg} / \mathrm{kg}$ within 10 minutes. Acidic saline of $\mathrm{pH} 3.3$ was used as vehicle instead of MK-8825. Nitroglycerin (Trinitrosan, Merck Serono, $250 \mu \mathrm{g} / \mathrm{kg} / \mathrm{h}$ ) was dissolved in $1 \mathrm{ml}$ isotonic saline for i.v. infusion.

\section{Data analysis and statistics}

Statistical tests were performed using Statistica 7.0 software (StatSoft, Tulsa, OK, USA). In the sample of experiments combining MK-8825/vehicle with nitroglycerin $(N=12 / 11)$ the course of activity was analysed by oneand two-way ANOVA with repeated measurements followed by Fisher's least significant difference (LSD)

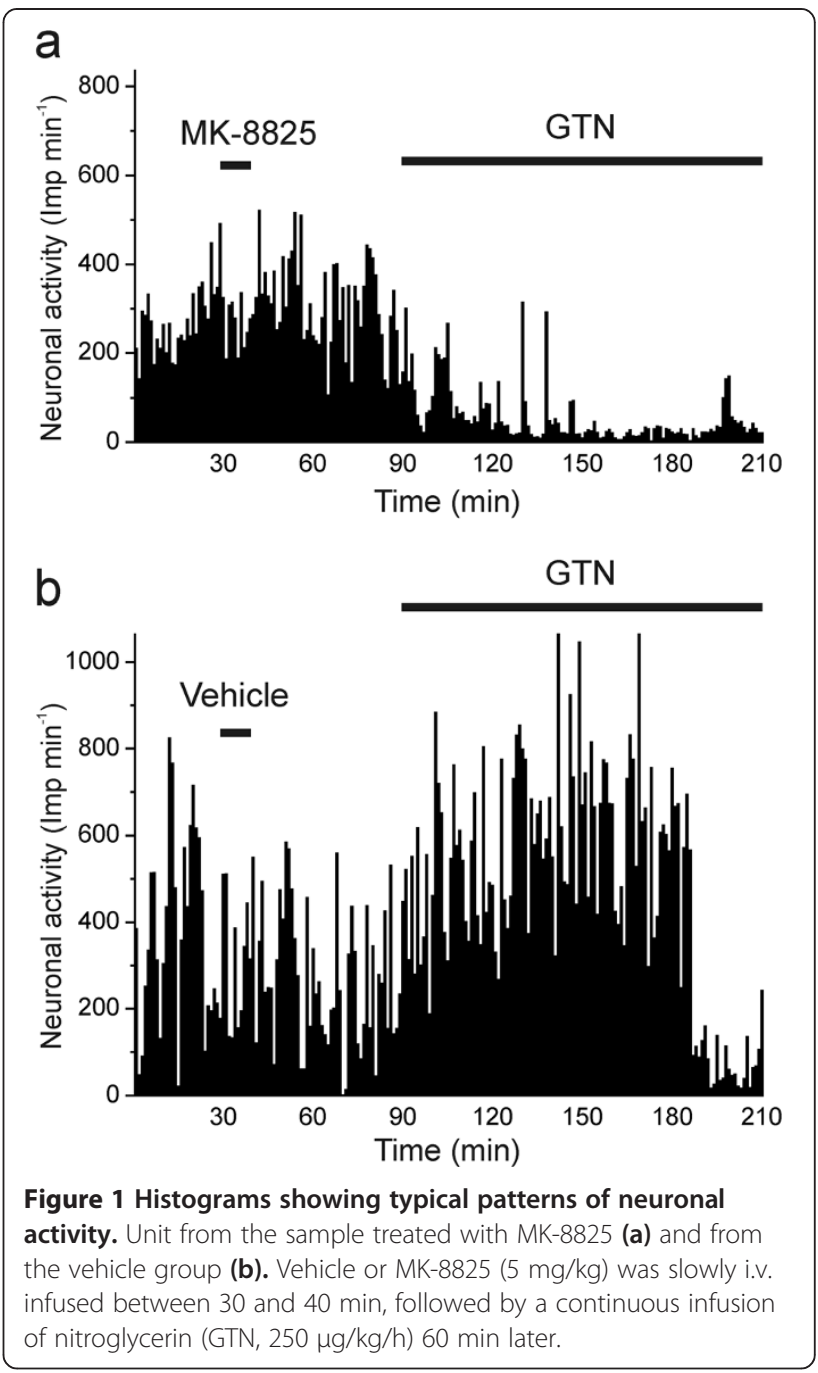

post hoc test using regular intervals of 10 and $30 \mathrm{~min}$. The Wilcoxon matched pairs test was used to compare the neuronal activity within periods of $30 \mathrm{~min}$ in the group of units treated only with nitroglycerin $(N=6$, normal distribution not verifiable). Differences were considered significant at $P<0.05$. For the diagrams the activity was normalised to the mean baseline activity.

\section{Results}

\section{General properties of neurons}

Twenty-nine units recorded in 28 experiments were included in this study. The recording sites were located $1.3-3.25 \mathrm{~mm}$ caudal to the obex, $0.35-1.75$ lateral to the midline and at depths of $386-1302 \mu \mathrm{m}$ below the dorsal surface of the medulla. The ongoing activity of these units during the baseline period of $30 \mathrm{~min}$ ranged from 7 to 1685 (mean 481) spikes per minute. The meningeal receptive fields of the units were mostly located close to the middle meningeal artery. The mechanical threshold, determined with graded von Frey filaments in 
the most sensitive center of the receptive fields, ranged from 0.78 to $11.8 \mathrm{mN}$. The units were activated by electrical square pulses (duration $1 \mathrm{~ms}$ ) applied to the meningeal receptive fields, thresholds were ranging from 0.4 to $2.4 \mathrm{~mA}$. The latencies after a single electrical pulse close above threshold ranged from 12 to $60 \mathrm{~ms}$. With an assumed conduction distance of $25 \mathrm{~mm}$ from the stimulation site to the caudal medulla the recorded units were concluded to be driven by slowly conducting $A \delta$ and/or $\mathrm{C}$-fibres from the dura mater. All units received convergent input from facial areas in the ophthalmic, maxillary or mandibular division of the trigeminal nerve as well as from the temporal muscle or the neck muscles and the periosteum around the cranial window.

Neuronal responses to MK- 8825 followed by nitroglycerin After recording of baseline activity the infusion of MK$8825(5 \mathrm{mg} / \mathrm{kg})$ was not accompanied by significant changes in activity (Figure 1a), though there was a slight tendency towards a transient increase in the whole sample (see Figure 2a-b). After one hour during the subsequent continuous infusion of nitroglycerin $(250 \mu \mathrm{g} / \mathrm{kg} / \mathrm{h})$ the activity decreased below baseline levels in the whole sample of units $\left(N=12\right.$, ANOVA, $F_{20,220}=2.90, P<$ 0.001 ). Finally the activity within all $10 \mathrm{~min}$ periods during the last $50 \mathrm{~min}$ was significantly lower compared to all 10 min periods before infusion of nitroglycerin (LSD test, $P<0.05$ each; Figure 2a). Comparing periods of 30 min between the MK- 8825 and the vehicle sample, two-way ANOVA with repeated measurements indicated a difference in time course $\left(F_{6,120}=2.73, P<0.02\right)$, which was due to a significant decrease in activity within the last 90 min of the MK- 8825 group compared to baseline and to the period of MK-8825 infusion (LSD test, $P<$ 0.05 each; Figure $2 b)$.

\section{Neuronal responses to vehicle followed by nitroglycerin}

The activity of units varied considerably following infusion of vehicle (saline $\mathrm{pH}$ 3.3) and nitroglycerin (Figure 1b). Repeated measures ANOVA indicated a significant change in activity during the recording time $\left(N=11\right.$, ANOVA, $\left.F_{20,200}=1.96, P=0.01\right)$. During the infusion of vehicle there was a tendency towards an increase in the whole sample without reaching significance (see Figure 2a-b). The subsequent infusion of nitroglycerin was accompanied by a significant increase in activity (Figure 1b) which in the whole sample of units was significant within the first $20 \mathrm{~min}$ and the period of 3040 min after onset of the nitroglycerin infusion compared to the baseline (LSD test, $P<0.05$ each; Figure 2a). In the second hour of nitroglycerin infusion the activity declined. Two-way ANOVA with repeated measurements for analysis of 30 min periods in the MK- 8825 and the vehicle sample showed that the activity was lowered within the last $30 \mathrm{~min}$ of the vehicle group compared to the period of nitroglycerin infusion. (LSD test, $P<0.05$; Figure $2 \mathrm{~b}$ ).

\section{Neuronal response to nitroglycerin alone}

To re-examine the apparent decrease in activity within the second hour of nitroglycerin infusion, we applied nitroglycerin without any other treatment for two hours in six additional experiments. The activity increased significantly during the second $30 \mathrm{~min}$ period after onset of the nitroglycerin infusion (Wilcoxon matched pairs test, $\mathrm{p}<0.05$ ) but during the second hour of nitroglycerin infusion it returned to control levels (Figure 2c).

In none of the experiments systemic parameters changed significantly during the infusions.

\section{Discussion}

In the present study we performed extracellular recordings in the caudal spinal trigeminal nucleus from neurons with receptive fields in the cranial dura mater. The activity of these neurons is a good integrative measure of meningeal nociception and is assumed to correlate with headaches in humans [23,24]. Previous experiments have shown that in most of these neurons intravenous infusion of nitrovasodilators like sodium nitroprusside or nitroglycerin induced a delayed or continuous increase in activity, which was reduced to baseline after infusion of the CGRP receptor antagonist olcegepant $[18,23]$. The main purpose of the present study was to examine if inhibition of CGRP receptors with the new CGRP receptor antagonist MK-8825 is also able to prevent an increase in neuronal activity induced by nitroglycerin.

\section{Study design and effects of nitroglycerin}

We have used a continuous low-dose infusion of nitroglycerin to avoid significant lowering of the blood pressure that could occur at higher doses. Since MK- 8825 must be dissolved in acidic saline $(\mathrm{pH} 3.3)$, the vehicle was titrated to the same $\mathrm{pH}$. The infusion of these acidic solutions was followed by a trend towards an increase in activity in several units without reaching statistical significance in the whole sample of experiments. We assume that the acidic solution was responsible for this tendency, though the acidic solution should have been rapidly buffered in the plasma. Acidic solutions have been shown to induce CGRP release in the hemisected rat head preparation [24] and to activate spinal trigeminal neurons when applied to meningeal receptive fields [25] but there are no data yet with systemic application of acidic substances.

In previous experiments, in which we used the same mode of nitroglycerin infusion, we observed an increase in spinal trigeminal activity that started immediately and reached significance $25 \mathrm{~min}$ after onset of the infusion 


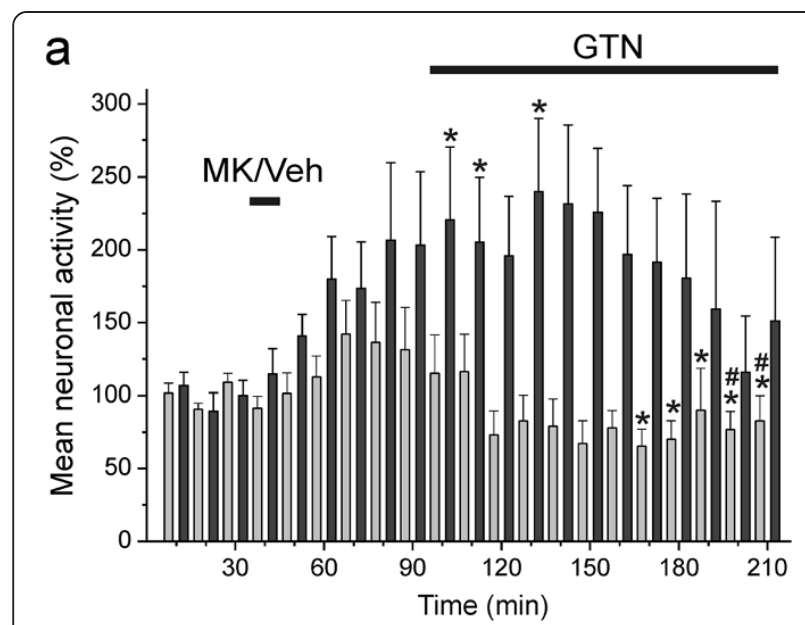

b
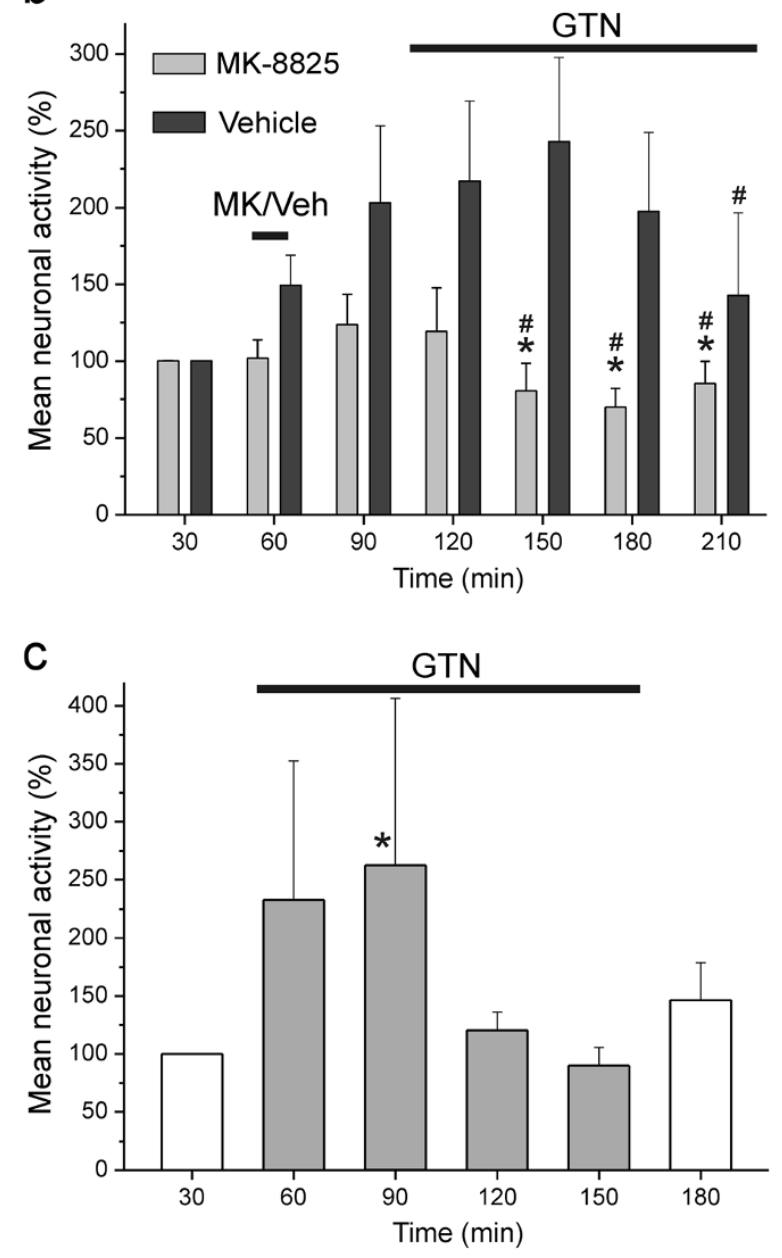

Figure 2 Histograms showing mean neuronal activity. Activity was normalised to the baseline of 10 min periods (a) and of $30 \mathrm{~min}$ periods (b) in the MK-8825 group (grey bars, $n=12$ ) and the vehicle group (black bars, $n=11$ ); error bars are s.e.m. (c) Mean normalised activity (+ s.e.m.) of 6 units treated with nitroglycerin (GTN) alone for two hours. Significant differences in activity compared to the baseline periods (0-30 $\mathrm{min}$ ) are indicated by a star and compared to periods after vehicle/MK-8825 infusion by \#; repeated measures ANOVA and LSD post hoc test $(\mathbf{a}, \mathbf{b})$ or WILCOXON (c).

[18]. In the present study we repeated these experiments with a longer observation time, since in the previous study the activity was observed only for one hour. It should be mentioned that the nitroglycerin effect is rather variable between different neurons suggesting that only a fraction of central neurons is readily under the control of NO. Within the first hour of nitroglycerin infusion the activity increased significantly in the whole sample of experiments but the increase did not outlast the second hour of infusion.

Nitroglycerin in clinically relevant concentrations has been shown to cause vasorelaxation not necessarily dependent of NO production, rather by direct activation of the soluble guanylate cyclase (sGC) dependent intracellular pathway $[26,27]$. Since vasorelaxation induced by nitroglycerin can be independent of CGRP release, it is not surprising that CGRP receptor inhibitors like telcagepant are not effective in inhibiting nitroglycerin induced vasodilation in humans [17]. We assume that the observed transient increase in activity of spinal trigeminal neurons is due to direct sGC activation. Nitroglycerin, though at a considerably higher systemic dose $(10 \mathrm{mg} / \mathrm{kg})$ as in the present study, has been shown to activate the transcription factor NF- $\mathrm{kB}[28]$ and the calmodulin dependent protein kinase II alpha (CamKII $\alpha$ ) [29] in the rat spinal trigeminal nucleus, which could explain transcriptional effects causing long-term neuronal changes. Therefore it seems likely that nitroglycerin and NO donors cause transient but also transcriptional effects with a delayed onset and long duration. The upregulation of CGRP and nNOS immunoreactivity in rat primary trigeminal afferents six hours after onset of a nitroglycerin infusion at the same dose as in the present study [30] and the increase in NOS-positive second order neurons, which continued during many hours [31,32], are certainly based on long-term transcriptional effects. Glutamate receptors in the spinal trigeminal nucleus seem to be involved in NO-sGC signalling in regard of both immediate neuronal effects [33] and transcriptional effects, which could be attenuated by the unspecific glutamate receptor inhibitor kynurenic acid [34].

Transient receptor potential channels type A1 (TRPA1) have been found to be expressed in peptidergic trigeminal afferents $[35,36]$ and to cause CGRP release followed by 
meningeal vasodilatation when activated by irritant environmental stimuli [37]. There is also evidence from recent experiments in our laboratory that NO species can induce CGRP release from meningeal afferents via activation of TRPA1 receptor channels, indicating that this pathway may come into account to trigger migraine [38]. This issue should be paid attention to, since TRPA1 can also be activated by volatile anaesthetics [39]. Therefore it was important in our experiments to hold the anaesthesia at a constant level to warrant reproducibility of the measurements.

\section{Effects of the CGRP receptor inhibitor MK-8825}

MK-8825 is related to the compound MK-3207, a CGRP receptor antagonist with high affinity to human but reduced affinity to rat CGRP receptors. MK-8825 has similar potency as MK-3207, but has a much higher unbound fraction in rat plasma. MK-3207 shows inhibition of capsaicin-induced dermal vasodilatation in rhesus monkey [40], and in an adaptive dose-ranging trial MK-3207 demonstrated a positive response on the primary 2-hour pain freedom endpoint and the secondary endpoint of 2-hour pain relief in migraine [41]. Both MK-3207 and MK-8825 are structurally distinct from telcagepant.

After pre-treatment with MK-8825 the infusion of nitroglycerin was not followed by the typical slow increase in neuronal activity. There was rather a tendency towards lowering of activity in the whole sample of experiments, and this decrease was finally significant in the last $90 \mathrm{~min}$ of recording. We conclude that this effect was due to the inhibition of CGRP receptors by MK-8825 and that CGRP receptors may be necessary for the action of nitroglycerin to generate neuronal activity.

Time-dependent differential effects of nitroglycerin, as discussed above, could explain the discrepancies between studies using 5-HT1B/D receptor agonists (triptans) to modulate nitroglycerin actions. It has been reported that the increase in nNOS immunoreactivity in the rat spinal trigeminal nucleus observed one hour after $10 \mathrm{mg} / \mathrm{kg}$ i.v. nitroglycerin was inhibited by sumatriptan administered shortly before the nitroglycerin infusion [42]. However, in a parallel study with the same systemic (s.c.) nitroglycerin dose and a similar dose of sumatriptan, no inhibition of the increased nNOS expression was found four hours after nitroglycerin [43]. In mice sumatriptan reduced allodynia induced by nitroglycerin, and in cats iontophoretically administered eletriptan normalised the elevated discharge rate of spinal trigeminal neurons after nitroglycerin [44], both acute experiments. Thus it seems that the fast (within one hour) appearing neuronal effects of nitroglycerin can be attenuated by blocking CGRP release or CGRP receptors, while later this is no longer possible. From this we can further conclude that the fast neuronal effects of nitroglycerin depend on the presence of CGRP, while for the longlasting effects probably based on gene transcription this is doubtful.

\section{Clinical implications}

The slow increase in spinal trigeminal activity induced by nitrovasodilators [23] is paralleled by clinical experiments in healthy persons and patients suffering from primary headaches, in which infusion of nitroglycerin caused delayed headaches [12-14]. The data of the present study suggest that inhibition of CGRP receptors could also be effective in preventing experimental headaches. In a cross-over study in patients suffering from migraine without aura, in which 13 patients received either olcegepant or placebo after a 20 min infusion of nitroglycerin, migraine developed in 7 patients after olcegepant and in 9 patients after placebo, and the headache scores were similar [45]. The authors concluded that a preventive effect of olcegepant for nitroglycerininduced migraine pain could not been confirmed. The discrepancy between this study and our experimental data, apart from species differences, may result from differing preconditions between the two study designs. In our study MK-8825 was infused 60 min prior to the continuous nitroglycerin infusion, whereas in the clinical experiments of the above study [45] olcegepant was infused after nitroglycerin. In our study the increase in activity occurred in the first hour and was transient, whereas the delayed headache attacks in the clinical study occurred after several hours. It seems likely that the increase in activity induced by nitroglycerin is a result of the presumed fast effects discussed above, whereas the delayed headaches belong to the long-term events based on gene transcription. Further experiments should clarify if pre-administration of a CGRP receptor inhibitor can also prevent the late events induced by nitroglycerin.

The second question is related to the site of action of CGRP. From animal experiments we know that CGRP applied on rat dura mater is not activating meningeal afferents [46]. Thus, if headache is induced by CGRP, it is most likely a central effect. Assuming that the effects of MK-8825 and olcegepant in meningeal antinociception and migraine therapy, respectively, may result from inhibition of central CGRP receptors, the effects depend essentially from the degree of blood brain penetration of both substances. The question to which extent CGRP receptor antagonists need to target central CGRP receptors for a therapeutic action is controversely discussed [47-49]. Animal experiments provide evidence for the involvement of central CGRP receptors to effectively inhibit spinal trigeminal activity [50]. Olcegepant is thought to penetrate the blood brain barrier (BBB) poorly, 
demonstrated by the lack of vascular effects on cerebral arteries in the study of Tvedskov et al. [45] but for MK-8825 such data are not available. The issue could possibly be solved by using CGRP $(8-37)$ as a CGRP receptor antagonist, which as a peptide should not pass the BBB.

\section{Mechanism of CGRP receptor inhibition}

If CGRP is required for the fast nociceptive processes induced by nitroglycerin but not for the delayed headaches, what is then the mechanism of CGRP receptor inhibition preventing nitroglycerin-induced increase in spinal trigeminal activity? CGRP is likely to operate as co-transmitter in the spinal trigeminal nucleus [51] and may be particularly important for initiation of central sensitisation [52]. In animals hypersensitive to CGRP due to over-expression of the CGRP receptor protein RAMP1, CGRP has been found to induce mechanical allodynia [53], most likely a central effect. Neuronal structures on the level of the first synapse are certainly central terminals of primary afferents, since CGRP receptor expression has been found in superficial laminae but not in second order neurons in the spinal trigeminal nucleus [54]. Fast sGC-induced processes, as discussed above, may facilitate nociceptive transmission. The delayed transcriptional processes induced by nitroglycerin include probably the upregulation of NO-producing neurons [31]. NO released by these neurons may operate as retrograde transmitter facilitating neurotransmitter release from primary trigeminal terminals, similar to neurons in the spinal dorsal horn, for which an analog function has been postulated [55]. Central sensitisation accompanying migraine attacks, typically diagnosed by cutaneous allodynia of trigeminal areas, may be the result of such long-term changes [56,57]. Triptans are no longer fully effective for migraine therapy after central sensitisation has developed [58].

The established role of CGRP as a key mediator in migraine is underlined by a recent report on elevated CGRP plasma levels during the interictal phases in chronic migraine [59]. In this increasingly prevalent disease a preventive therapy targeting CGRP may be even more important, particularly if the pain is refractory to conventional therapies. Thus it is encouraging that, among others, several approaches to block CGRP or CGRP receptors are in an experimental state, including antibodies and mirror-image RNAs (so-called Spiegelmers) binding to CGRP or CGRP receptors as well as new CGRP receptor antagonists like those discussed in the present paper [60-62]. To guide these developments, a better understanding of the events linked to CGRP release and to CGRP actions is desirable, which is the intention of the present and further preclinical studies.

\section{Conclusions}

In the present experiments inhibition of CGRP receptors prevented the increase in spinal trigeminal activity induced by infusion of nitroglycerin, later followed by a decrease in activity below baseline. We assume that CGRP receptor inhibition operates preferably in the spinal trigeminal nucleus to block neuronal activity induced by activation of intracellular NO receptors (soluble guanylate cyclase) at an early state. Assuming that similar mechanisms are involved in the development of spontaneous headache attacks, CGRP receptor inhibition may be also preventive in migraine.

\section{Competing interests}

The authors declare to have no competing interests.

\section{Authors' contributions}

SF and SA performed the experiments. SF and KM analysed the data and drafted the manuscript. KM instructed the experiments and revised the manuscript. All authors read and approved the final manuscript.

\section{Acknowledgements}

This work was supported in part by the DFG (Deutsche Forschungsgemeinschaft) and Merck \& Co. Inc., NJ, USA. MK-8825 was a gift from Merck \& Co. Inc. We thank Christopher Salvatore and lan Bell for valuable informations about MK-8825.

Received: 2 October 2013 Accepted: 16 November 2013

Published: 20 November 2013

\section{References}

1. Arulmani U, Maassenvandenbrink A, Villalon CM, Saxena PR (2004) Calcitonin gene-related peptide and its role in migraine pathophysiology. Eur J Pharmacol 500:315-330

2. Olesen J, Thomsen LL, Lassen LH, Olesen IJ (1995) The nitric oxide hypothesis of migraine and other vascular headaches. Cephalalgia 15:94-100

3. Bellamy JL, Cady RK, Durham PL (2006) Salivary levels of CGRP and VIP in rhinosinusitis and migraine patients. Headache 46:24-33

4. Edvinsson L, Goadsby PJ (1995) Neuropeptides in the cerebral circulation: relevance to headache. Cephalalgia 15:272-276

5. Ashina M, Bendtsen $L$, Jensen R, Schifter S, Jansen-Olesen I, Olesen J (2000) Plasma levels of calcitonin gene-related peptide in chronic tension-type headache. Neurology 55:1335-1340

6. Tvedskov JF, Lipka K, Ashina M, Iversen HK, Schifter S, Olesen J (2005) No increase of calcitonin gene-related peptide in jugular blood during migraine. Ann Neurol 58:561-568

7. Lassen LH, Haderslev PA, Jacobsen VB, Iversen HK, Sperling B, Olesen J (2002) CGRP may play a causative role in migraine. Cephalalgia 22:54-61

8. Fanciullacci M, Alessandri M, Figini M, Geppetti P, Michelacci S (1995) Increase in plasma calcitonin gene-related peptide from the extracerebral circulation during nitroglycerin-induced cluster headache attack. Pain 60:119-123

9. Connor KM, Shapiro RE, Diener HC, Lucas S, Kost J, Fan X, Fei K, Assaid C, Lines C, Ho TW (2009) Randomized, controlled trial of telcagepant for the acute treatment of migraine. Neurology 73:970-977

10. Olesen J, Diener HC, Husstedt IW, Goadsby PJ, Hall D, Meier U, Pollentier S, Lesko LM (2004) Calcitonin gene-related peptide receptor antagonist BIBN 4096 BS for the acute treatment of migraine. N Engl J Med 350:1104-1110

11. Ho TW, Mannix LK, Fan X, Assaid C, Furtek C, Jones CJ, Lines CR, Rapoport AM (2007) Randomized controlled trial of an oral CGRP antagonist, MK0974, in acute treatment of migraine. Neurology 70:1304-1312

12. Christiansen I, Thomsen LL, Daugaard D, Ulrich V, Olesen J (1999) Glyceryl trinitrate induces attacks of migraine without aura in sufferers of migraine with aura. Cephalalgia 19:660-667

13. Ashina M, Bendtsen $L$, Jensen R, Olesen J (2000) Nitric oxide-induced headache in patients with chronic tension-type headache. Brain 123:1830-1837 
14. Ekbom K (1968) Nitrolglycerin as a provocative agent in cluster headache. Arch Neurol 19:487-493

15. Lassen LH, Ashina M, Christiansen I, Ulrich V, Olesen J (1997) Nitric oxide synthase inhibition in migraine. Lancet 349:401-402

16. Hoivik HO, Laurijssens BE, Harnisch LO, Twomey CK, Dixon RM, Kirkham AJ, Williams PM, Wentz AL, Lunnon MW (2010) Lack of efficacy of the selective iNOS inhibitor GW274150 in prophylaxis of migraine headache. Cephalalgia 30:1458-1467

17. Van der Schueren BJ, Lunnon MW, Laurijssens BE, Guillard F, Palmer J, Van Hecken A, Depre M, Vanmolkot FH, de Hoon JN (2009) Does the unfavorable pharmacokinetic and pharmacodynamic profile of the iNOS inhibitor GW273629 lead to inefficacy in acute migraine? I Clin Pharmacol 49:281-290

18. Koulchitsky S, Fischer M, Messlinger K (2009) Calcitonin gene-related peptide receptor inhibition reduces neuronal activity induced by prolonged increase in nitric oxide in the rat spinal trigeminal nucleus. Cephalalgia 29:408-417

19. De Col R, Koulchitsky SV, Messlinger KB (2003) Nitric oxide synthase inhibition lowers activity of neurons with meningeal input in the rat spinal trigeminal nucleus. Neuroreport 14:229-232

20. Fischer MJ, Koulchitsky S, Messlinger K (2005) The nonpeptide calcitonin gene-related peptide receptor antagonist BIBN4096BS lowers the activity of neurons with meningeal input in the rat spinal trigeminal nucleus. J Neurosci 25:5877-5883

21. Bell IM, Stump CA, Gallicchio SN, Staas DD, Zartman CB, Moore EL, Sain N, Urban M, Bruno JG, Calamari A, Kemmerer AL, Mosser SD, Fandozzi C, White RB, Zrada MM, Selnick HG, Graham SL, Vacca JP, Kane SA, Salvatore CA (2012) MK-8825: a potent and selective CGRP receptor antagonist with good oral activity in rats. Bioorg Med Chem Lett 22:3941-3945

22. Burstein R, Yamamura H, Malick A, Strassman AM (1998) Chemical stimulation of the intracranial dura induces enhanced responses to facial stimulation in brain stem trigeminal neurons. J Neurophysiol 79:964-982

23. Koulchitsky S, Fischer MJ, De Col R, Schlechtweg PM, Messlinger K (2004) Biphasic response to nitric oxide of spinal trigeminal neurons with meningeal input in rat-possible implications for the pathophysiology of headaches. J Neurophysiol 92:1320-1328

24. Averbeck B, Reeh PW (2001) Interactions of inflammatory mediators stimulating release of calcitonin gene-related peptide, substance $P$ and prostaglandin E(2) from isolated rat skin. Neuropharmacology 40:416-423

25. Schepelmann K, Ebersberger A, Pawlak M, Oppmann M, Messlinger K (1999) Response properties of trigeminal brain stem neurons with input from dura mater encephali in the rat. Neuroscience 90:543-554

26. Nunez C, Victor VM, Tur R, Alvarez-Barrientos A, Moncada S, Esplugues JV, D'Ocon P (2005) Discrepancies between nitroglycerin and NO-releasing drugs on mitochondrial oxygen consumption, vasoactivity, and the release of NO. Circ Res 97:1063-1069

27. Kleschyov AL, Oelze M, Daiber A, Huang Y, Mollnau H, Schulz E, Sydow K, Fichtlscherer B, Mulsch A, Munzel T (2003) Does nitric oxide mediate the vasodilator activity of nitroglycerin? Circ Res 93:e104-e112

28. Greco R, Tassorelli C, Cappelletti D, Sandrini G, Nappi G (2005) Activation of the transcription factor NF-kappaB in the nucleus trigeminalis caudalis in an animal model of migraine. Neurotoxicology 26:795-800

29. Vamos E, Fejes A, Koch J, Tajti J, Fulop F, Toldi J, Pardutz A, Vecsei L (2010) Kynurenate derivative attenuates the nitroglycerin-induced CamKllalpha and CGRP expression changes. Headache 50:834-843

30. Dieterle A, Fischer MJ, Link AS, Neuhuber WL, Messlinger K (2011) Increase in. Cephalalgia 31:31-42

31. Schlechtweg PM, Roder J, Fischer MJ, Neuhuber W, Messlinger K (2009) Increase in NADPH-diaphorase-positive and neuronal NO synthase immunoreactive neurons in the rat spinal trigeminal nucleus following infusion of a NO donor-evidence for a feed-forward process in NO production involved in trigeminal nociception. Cephalalgia 29:566-579

32. Pardutz A, Krizbai I, Multon S, Vecsei L, Schoenen J (2000) Systemic nitroglycerin increases $n N O S$ levels in rat trigeminal nucleus caudalis. Neuroreport 11:3071-3075

33. Lambert GA, Hoskin KL, Zagami AS (2004) Nitrergic and glutamatergic neuronal mechanisms at the trigeminovascular first-order synapse. Neuropharmacology 47:92-105

34. Vamos E, Pardutz A, Varga H, Bohar Z, Tajti J, Fulop F, Toldi J (2009) Vecsei L: I-kynurenine combined with probenecid and the novel synthetic kynurenic acid derivative attenuate nitroglycerin-induced nNOS in the rat caudal trigeminal nucleus. Neuropharmacology 57:425-429
35. Huang D, Li S, Dhaka A, Story GM, Cao YQ (2012) Expression of the transient receptor potential channels TRPV1, TRPA1 and TRPM8 in mouse trigeminal primary afferent neurons innervating the dura. Mol Pain 8:66

36. Kim YS, Son JY, Kim TH, Paik SK, Dai Y, Noguchi K, Ahn DK, Bae YC (2010) Expression of transient receptor potential ankyrin 1 (TRPA1) in the rat trigeminal sensory afferents and spinal dorsal horn. J Comp Neurol 518:687-698

37. Kunkler PE, Ballard CJ, Oxford GS, Hurley JH (2011) TRPA1 receptors mediate environmental irritant-induced meningeal vasodilatation. Pain 152:38-44

38. Benemei S, De CF, Fusi C, Rossi E, Lupi C, Geppetti P (2013) TRPA1 and other TRP channels in migraine. J Headache Pain 14:71

39. Matta JA, Cornett PM, Miyares RL, Abe K, Sahibzada N, Ahern GP (2008) General anesthetics activate a nociceptive ion channel to enhance pain and inflammation. Proc Natl Acad Sci U S A 105:8784-8789

40. Salvatore CA, Moore EL, Calamari A, Cook JJ, Michener MS, O'Malley S, Miller PJ, Sur C, Williams DL, Jr, Zeng Z, Danziger A, Lynch JJ, Regan CP, Fay JF, Tang YS, Li CC, Pudvah NT, White RB, Bell IM, Gallicchio SN, Graham SL, Selnick HG, Vacca JP, Kane SA (2010) Pharmacological properties of MK3207, a potent and orally active calcitonin gene-related peptide receptor antagonist. J Pharmacol Exp Ther 333:152-160

41. Hewitt DJ, Aurora SK, Dodick DW, Goadsby PJ, Ge YJ, Bachman R, Taraborell D, Fan X, Assaid C, Lines C, Ho TW (2011) Randomized controlled trial of the CGRP receptor antagonist MK-3207 in the acute treatment of migraine. Cephalalgia 31:712-722

42. Suwattanasophon C, Phansuwan-Pujito P, Srikiatkhachorn A (2003) 5-HT(1B/ 1D) serotonin receptor agonist attenuates nitroglycerin-evoked nitric oxide synthase expression in trigeminal pathway. Cephalalgia 23:825-832

43. Pardutz A, Szatmari E, Vecsei L, Schoenen J (2004) Nitroglycerin-induced nNOS increase in rat trigeminal nucleus caudalis is inhibited by systemic administration of lysine acetylsalicylate but not of sumatriptan. Cephalalgia 24:439-445

44. Lambert GA, Boers PM, Hoskin KL, Donaldson C, Zagami AS (2002) Suppression by eletriptan of the activation of trigeminovascular sensory neurons by glyceryl trinitrate. Brain Res 953:181-188

45. Tredskov JF, Tfelt-Hansen P, Petersen KA, Jensen LT, Olesen J (2010) CGRP receptor antagonist olcegepant (BIBN4096BS) does not prevent glyceryl trinitrate-induced migraine. Cephalalgia 30:1346-1353

46. Levy D, Burstein R, Strassman AM (2005) Calcitonin gene-related peptide does not excite or sensitize meningeal nociceptors: implications for the pathophysiology of migraine. Ann Neurol 58:698-705

47. Tfelt-Hansen P, Olesen J (2011) Possible site of action of CGRP antagonists in migraine. Cephalalgia 31:748-750

48. Edvinsson L (2008) CGRP blockers in migraine therapy: where do they act? Br J Pharmacol 155:967-969

49. Edvinsson L, Tfelt-Hansen P (2008) The blood-brain barrier in migraine treatment. Cephalalgia 28:1245-1258

50. Sixt ML, Messlinger K, Fischer MJ (2009) Calcitonin gene-related peptide receptor antagonist olcegepant acts in the spinal trigeminal nucleus. Brain 132:3134-3141

51. Storer RJ, Akerman S, Goadsby PJ (2004) Calcitonin gene-related peptide (CGRP) modulates nociceptive trigeminovascular transmission in the cat. Br J Pharmacol 142:1171-1181

52. Seybold VS (2009) The role of peptides in central sensitization. Handb Exp Pharmacol 194:451-491

53. de Marquez PB, Hammond DL, Russo AF (2009) Genetic enhancement of calcitonin gene-related Peptide-induced central sensitization to mechanical stimuli in mice. J Pain 10:992-1000

54. Lennerz JK, Ruhle V, Ceppa EP, Neuhuber WL, Bunnett NW, Grady EF, Messlinger K (2008) Calcitonin receptor-like receptor (CLR), receptor activitymodifying protein 1 (RAMP1), and calcitonin gene-related peptide (CGRP) immunoreactivity in the rat trigeminovascular system: differences between peripheral and central CGRP receptor distribution. J Comp Neurol 507:1277-1299

55. Aimar P, Pasti L, Carmignoto G, Merighi A (1998) Nitric oxide-producing islet cells modulate the release of sensory neuropeptides in the rat substantia gelatinosa. J Neurosci 18:10375-10388

56. Bernstein C, Burstein R (2012) Sensitization of the trigeminovascular pathway: perspective and implications to migraine pathophysiology. J Clin Neurol 8:89-99

57. Burstein R, Cutrer MF, Yarnitsky D (2000) The development of cutaneous allodynia during a migraine attack clinical evidence for the sequential 
recruitment of spinal and supraspinal nociceptive neurons in migraine. Brain 123:1703-1709

58. Burstein R, Collins B, Jakubowski M (2004) Defeating migraine pain with triptans: a race against the development of cutaneous allodynia. Ann Neurol 55:19-26

59. Cernuda-Morollon E, Larrosa D, Ramon C, Vega J, Martinez-Camblor P, Pascual J (2013) Interictal increase of CGRP levels in peripheral blood as a biomarker for chronic migraine. Neurology 81:1191-1196

60. Dolgin E (2013) Antibody drugs set to revive flagging migraine target. Nat Rev Drug Discov 12:249-250

61. Lionetto L, Negro A, Palmisani S, Gentile G, Del Fiore MR, Mercieri M, Simmaco M, Smith T, Al-Kaisy A, Arcioni R, Martelletti P (2012) Emerging treatment for chronic migraine and refractory chronic migraine. Expert Opin Emerg Drugs 17:393-406

62. Recober A, Russo AF (2009) Calcitonin gene-related peptide: an update on the biology. Curr Opin Neurol 22:241-246

doi:10.1186/1129-2377-14-93

Cite this article as: Feistel et al:: The calcitonin gene-related peptide receptor antagonist MK-8825 decreases spinal trigeminal activity during nitroglycerin infusion. The Journal of Headache and Pain 2013 14:93.

\section{Submit your manuscript to a SpringerOpen ${ }^{\circ}$} journal and benefit from:

- Convenient online submission

- Rigorous peer review

- Immediate publication on acceptance

- Open access: articles freely available online

- High visibility within the field

- Retaining the copyright to your article

Submit your next manuscript at $\boldsymbol{\wedge}$ springeropen.com 